\title{
Immunohistochemical analysis of adhesive papillae of Clavelina lepadiformis (Müller, 1776) and Clavelina phlegraea (Salfi, 1929) (Tunicata, Ascidiacea)
}

\author{
R. Pennati, S. Groppelli, F. De Bernardi, F. Mastrototaro, ${ }^{1}$ G. Zega \\ Department of Biology, University of Milan, Milano; ${ }^{1}$ Department of Biology, University of Bari, Bari, Italy
}

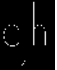

(C)2009 European Journal of Histochemistry

Almost all ascidian larvae bear three mucus secreting and sensory organs, the adhesive papillae, at the anterior end of the trunk, which play an important role during the settlement phase. The morphology and the cellular composition of these organs varies greatly in the different species. The larvae of the Clavelina genus bear simple bulbous papillae, which are considered to have only a secretory function. We analysed the adhesive papillae of two species belonging to this genus, $C$. lepadiformis and C. phlegraea, by histological sections and by immunolocalisation of $\beta$-tubulin and serotonin, in order to better clarify the cellular composition of these organs. We demonstrated that they contain at least two types of neurons: central neurons, bearing microvilli, and peripheral ciliated neurons. Peripheral neurons of $\mathrm{C}$. lepadiformis contain serotonin. We suggest that these two neurons play different roles during settlement: the central ones may be chemo- or mechanoreceptors that sense the substratum, and the peripheral ones may be involved in the mechanism that triggers metamorphosis.

Key words: Settlement, neurotransmitter, serotonin, $\beta$-tubulin, papillary nerves, metamorphosis.

Correspondence: Roberta Pennati,

Dipartimento di Biologia, via Celoria 26, 7B,

20133 Milano, Italy

Tel. +39.02.50314765.

Fax: +39.02 .50314802$

E-mail: roberta.pennati@unimi.it

Paper accepted on December 9, 2008

European Journal of Histochemistry

2009; vol. 53 issue 1 (January-March): 25-34
A scidians (phylum Chordata; subphylum Tunicata) are sessile filter-feeding organisms that can be found in all benthic marine environments and develop through a swimming tadpole larva. Larvae of colonial ascidians have a short planktonic life that can vary from minutes to hours (Burighel and Cloney, 1997). Prior to metamorphosis, the larva attaches to the substratum by means of peculiar organs of ectodermic origin, located in the anterior region of the trunk. These organs, known as adhesive papillae, secrete sticky substances and effect primary adhesion of the larva to the substrate (Cloney, 1977). They have an important role in the initiation of settlement and metamorphosis and there is evidence that, at least in some species, they participate in substrate selection (Torrence and Cloney, 1983; Svane and Young, 1989; Groppelli et al., 2003). In many species, they are organised in a triangular field, whereas in others they are aligned along the mid-sagittal plane of the trunk. Adhesive papillae have been classified into two types: eversible papillae, typical of some colonial species, composed by several cell types and rapidly changing shape as they touch the substrate, and non-eversible papillae, typical of solitary species, which do not change shape after settlement (Burighel and Cloney, 1997).

With few exceptions, all adhesive papillae are formed by elongated secretory and sensory cells, which are recognised as primary neurons (Cloney, 1977, 1979). It has been proposed that sensory cells may detect the chemical and physical characteristics of the substratum at potential sites for settlement and metamorphosis (Young and Braithwaite, 1980; Groppelli et al., 2003). The presence of primary neurons in the papillae has been reported in the larvae of several species such as Distaplia occidentalis, Diplosoma macdonaldi, Phallusia mammillata, Ciona intestinalis and Ascidia malaca (Cloney, 1977; Torrence and Cloney, 
1983; Sotgia et al., 1998; Takamura, 1998; Gianguzza et al., 1999). These neurons have axons that join together to form the papillary nerves that enter the central nervous system at the level of the sensory vesicle (Imai and Meinertzhagen, 2007).

Recently, different neurotransmitters have been localised in the sensory neurons of the papillae of different species. The presence of GABAergic neurons has been reported in the papillae of Ciona savygni (Brown et al., 2005) and of Ciona intestinalis (Zega et al., 2008), while serotonergic neurons have been localised in the papillae of Phallusia mammillata (Pennati et al., 2001) and Botrylloides leachi (Pennati et al., 2007). Moreover, it has been demonstrated that serotonin plays a role in the mechanism triggering metamorphosis in ascidians (Zega et al., 2005).

After attachment, all papillae retract to draw the larva closer to the substratum. In the colonial ascidian Distaplia occidentalis, the process of retraction is reversibly inhibited by cytochalasin $B$, suggesting that microfilaments are involved in this process (Cloney, 1979).

Clavelina lepadiformis is a colonial species, whose larvae bear non-eversible simple bulbous papillae. They have been described as being formed only by columnar glandular cells, whose secreted material is responsible for the sticky properties of the organ. These papillae do not contain sensory cells and were considered the simplest among those studied (Turon, 1991).

In this work, the morphology of the adhesive papillae of $C$. lepadiformis and $C$. phlegraea was further investigated by histological analysis and immunolabelling techniques in order to clarify the actual cellular composition and function of these organs.

\section{Materials and Methods}

\section{Animals}

Colonies of Clavelina lepadiformis were collected in the locality of Roscoff (France) in July 2007, during the sexual reproduction period of this species. Colonies of Clavelina phlegraea were collected by scuba diving in the gulf of Taranto (Italy) in September 2007. Naturally released swimming larvae were collected by means of a glass pipette, rinsed in Millipore-filtered seawater (MFSW), fixed in $4 \%$ paraformaldehyde in $0.1 \mathrm{M} \mathrm{PBS} \mathrm{pH}$
7.4 for 1 hour at room temperature and stored in $70 \%$ ethanol at $-20^{\circ} \mathrm{C}$ until further processing.

\section{Histology}

After rehydration in an alcohol series, fixed larvae were stained in $1 \%$ borax-carmine for $2 \mathrm{~h}$, and were then embedded in Technovit 7100 plastic (Heraeus Kulzer GmbH, Werheim, Germany) and sectioned at $5 \mu \mathrm{m}$. Sections were stained with $0.5 \%$ methylene-blue in water for a few minutes and mounted in Entellan (Merck, Italy).

\section{Immunohistochemistry}

After rehydration, fixed larvae were rinsed with $0.1 \mathrm{M}$ PBS, and processed for immunolocalisation experiments according to the method described by Zega et al. (2005). Samples were incubated at $4^{\circ} \mathrm{C}$ for $48 \mathrm{~h}$ with anti-human 5-hydroxytryptamine antibody (Medak), diluted 1:400 in PBS/heat inactivated Normal Goat Serum (1:1). The larvae were rinsed several times in PBT (PBS plus $0.2 \%$ Tween-20) and incubated overnight with monoclonal anti- $\beta$-tubulin antibody (clone 2-28-33; Sigma, Italy) diluted $1: 200$ in PBS/heat inactivated Normal Goat Serum (1:1). Anti 5-HT antibody was detected by FITC-conjugated anti rabbit IgG secondary antibody and anti $\beta$-tubulin antibody was detected by TRITC-conjugated anti mouse IgG secondary antibody. Specimens were mounted in 1,4diazabicyclo $[2,2,2]$ octane (DABC0, Sigma, Italy) plus MOWIOL (Sigma, Italy) on microscope slides. As negative controls, larvae were processed without incubation in primary antibodies. In control experiments, specimens did not exhibit detectable fluorescence. Samples were examined using a Leica TCSNT confocal laser scanning microscope (Leica Microsystems, Heidelberg, Germany), equipped with an argon/krypton, $75 \mathrm{~mW}$ multiline laser.

\section{Results}

\section{Morphological and histological analysis}

Clavelina lepadiformis forms colonies with zooids up to $3 \mathrm{~cm}$ in length (Figure $1 \mathrm{~A}$ ) that are completely free with branched stolons approaching but never fused $C$. phegraea forms large colonies with club-shaped lobes with groups of zooids (2-4) (Figure 2 A) (Brunetti, 1987). Moreover, the external wall of the brood pouch of $C$. lepadiformis presents a characteristic pigmentation, while it is unpig- 

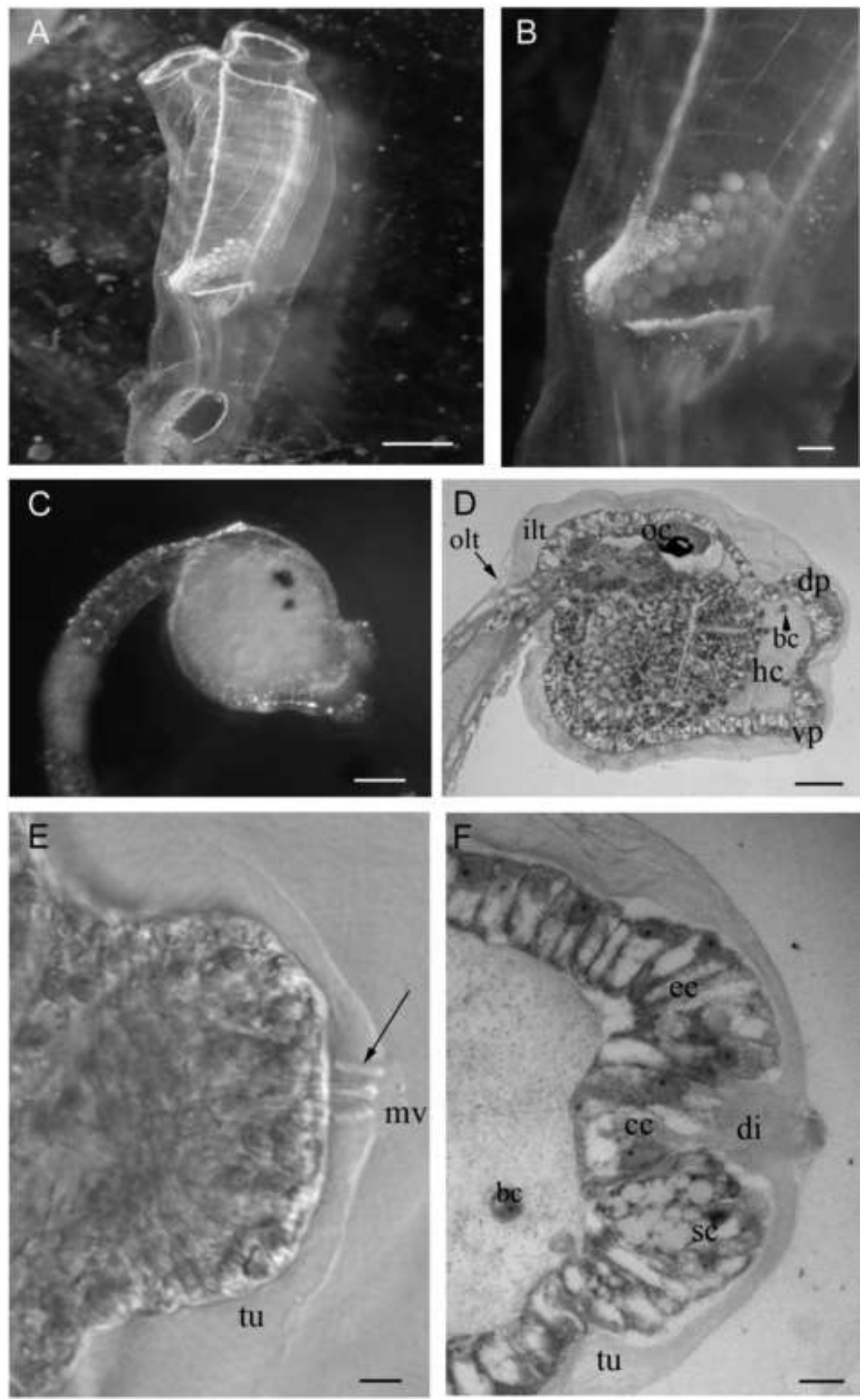

Figure 1. Clavelina lepadiformis (A) An isolated zooid. (B) Magnification of A showing the embryos incubated in the atrial chamber. (C) Swimming larva. (D) Longitudinal section of the trunk region of a larva, showing the large haemocoelic cavity (hc) under the papillae. bc: blood cell; dp: dorsal papilla; ilt: inner layer of tunic; oc: ocellus; olt: outer layer of tunic vp: ventral papilla. (E) Transmission microscopy image of a bulbous papilla showing the digitiform processes (arrow) of the central cells passing through the tunic (tu) and bearing microvilli (mv). (F) Longitudinal section of a papilla showing different cell types: central elongated cells (cc) with digitiform processes (di), emerging from the tunic (tu); secretory cells (sc) with big vacuoles; elongated supportive cells (ec). Scale bar: A 5 mm; B 1 mm; C 100 m; D $50 \mu \mathrm{m} ; \mathrm{E}, \mathrm{F} 10 \mu \mathrm{m}$. 

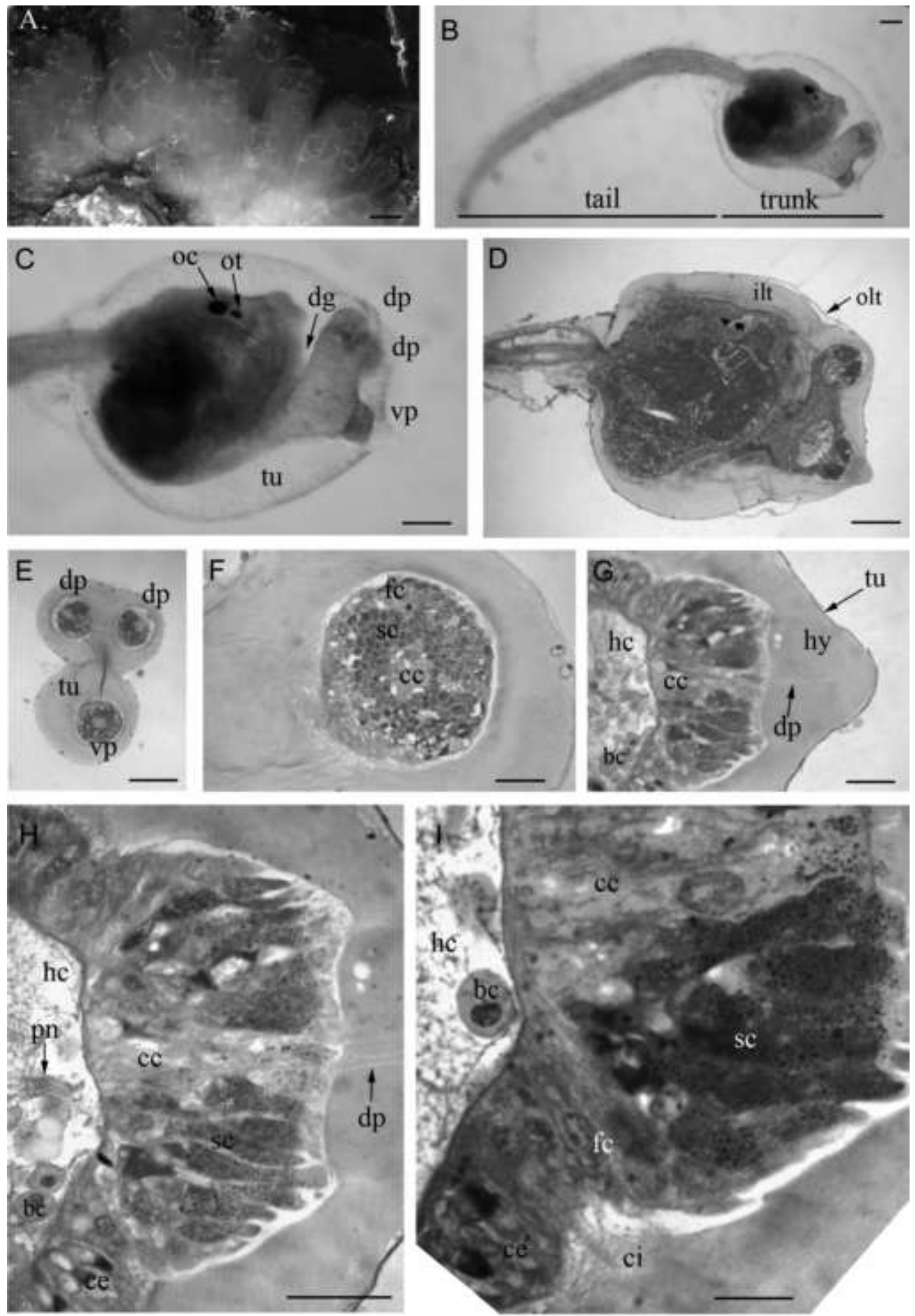

Figure 2. Clavelina phlegraea (A) A colony with several zooids. (B) A swimming larva of C. phlegraea. tu: tunic. C Magnification of the trunk region of the larva showing the disposition of the three adhesive papillae, two dorsal ones (dp) and a ventral one (vp). The papillae are borne by the anterior region of the trunk, which is separated by a deep dorsal groove (dg) from the rest of the trunk. It is possible to observe the two pigmented organs of the sensory vesicle, the ocellus (oc) and the otolith (ot). (D) Longitudinal section of the trunk of a C. phlegraea larva. int: inner layer of tunic; olt outer layer of tunic. (E) Cross section of the three adhesive papillae showing their disposition as the vertices of an isosceles triangle. (F) Magnification of the ventral papilla, showing the concentric arrangement of different cellular types. (G) Longitudinal section of a ventral papilla. It is possible to observe the hyaline cup (hy) crossed by digitiform processes (dp) of the central cells (cc); and the haemocoelic cavity (hc) under the papilla. (H) Magnification of G showing the secretory cell (sc), rich in small vacuoles, surrounding the central cells (cc). It is possible to observe the papillary nerve (pn) in the haemocoelic cavity (hc). (I) Detail of a histological section of a papilla showing the presence of fusiform cells (fc) bearing cilia (ci) at the base of the papilla. bc: blood cell. Scale bar: A 1 cm; B, C, D, E $100 \mu \mathrm{m} ;$ F, G, H 20 m; I $10 \mu \mathrm{m}$. 
mented in the co-generic C. phegraea (Brunetti, 1987).

Despite the differences between colonies, C. lepadiformis and $C$. phlegraea larvae share many common features, thus where not otherwise specified, it is intended that the description applies to both species.

The eggs develop in the atrial cavity (Figure $1 \mathrm{~A}$, B). After hatching, the larvae start to swim actively for about 2 hours. The larval body is characterised by a large trunk and a locomotory tail (Figure 1 C, 2 B). At the anterior end of the trunk the three adhesive papillae are arranged in a triangular field, two dorsal and one ventral (Figure $1 \mathrm{C}$, $2 \mathrm{C}, \mathrm{E}$ ) and are borne by a sort of peduncle, formed by the anterior-most part of the trunk, which is separated from the rest of the body by a dorsal groove. This groove is deeper in C. phlegraea than in C. lepadiformis, so that the anterior part of the trunk is joined to the rest of the body by a small ventral peduncle. The larva is completely covered by two layers of tunic, an outer one and an inner one (Figure 1 D, 2 D).

The adhesive papillae consist of three protrusions that secrete sticky substances, each one being about $50 \mu \mathrm{m}$ long and $100 \mu \mathrm{m}$ wide at the base (Figure 1 D, 2 D). The anterior part of the trunk region consists of a monolayer epithelium, which lies on a basal lamina. The basal lamina of the papillae delimits a lacuna, in which a few round blood cells are dispersed (Figure $1 \mathrm{D}, F ; 2 \mathrm{D}, \mathrm{G}$ ). In each papilla, the monolayer epithelium is formed by elongated cells, while in the surrounding area the epithelial cells are less elongated (Figure $1 \mathrm{~F}, 2 \mathrm{H}$ ).

Three cellular types are recognisable in the midsagittal sections of the papillae. Cells of the first type are localised in the central portion of the papilla (Figure $2 \mathrm{~F}$ ) and have an elongated fusiform shape (Figure $2 \mathrm{H}$ ). These cells bear digitiform processes that are clearly visible in whole mount specimens of $C$. lepadiformis (Figure $1 \mathrm{E}$ ). These processes pass through the inner layer of the tunic and extend towards the apex of the papilla (Figure 1 F, 2 G). Over each papilla, the larvae of C. phlegraea bear a big hyaline cup, about $50 \mu \mathrm{m}$ high, as previously described in other species (Burighel and Cloney, 1997); this is thought to store the secreted mucus (Figure $2 \mathrm{G}$ ). The digitiform processes of the central cells extend through the hyaline cup (Figure $2 G, H$ ). The hyaline cup has never been observed in C. lepadiformis larvae (Figure $1 \mathrm{~F}$ ). Cells of the second type are displaced in the peripheral portion of the papilla, surrounding the central fusiform cells, and are elongated and rich in vesicles (Figure I $F, 2 F, H$ ). In $C$. lepadiformis larvae, these vesicles are large and are filled with a clear substance, most probably mucus (Figure $1 \mathrm{~F}$ ). In C. phlegraea larvae, the vesicles in the peripheral cells are smaller, more numerous and more intensively stained than those of the other species (Figure $2 \mathrm{H}$ ). Cells of a third type are situated in a marginal position of the papillary body, are elongated with no visible vesicles and most probably have a supportive function. These cells are more numerous in $C$. lepadiformis (Figure $1 \mathrm{~F}$ ) than in $C$. phlegraea, in which they are barely visible. In $C$. phlegraea, ciliated cells and papillary nerves passing through the haemocoelic cavity were recognized at the base of the papilla Figure $2 \mathrm{H}, \mathrm{I}$ ).

\section{Immunohistochemical analysis}

The entire nervous system of the larvae of $C$. lepadiformis and $C$. phlegraea was revealed by the monoclonal anti $\beta$-tubulin antibody, which efficiently labels neural structures in ascidian larvae (Pennati et al., 2001, 2007). The immunostaining signal was particularly strong in the central nervous system along the entire neural tube, comprising the sensory vesicle and the nerve cord (Figure $3 \mathrm{~A}, \mathrm{G}$ ). In C. lepadiformis, immunolabelling experiments revealed the presence of immunopositive fibres leading from the papillae to the CNS (Figure $3 \mathrm{~A}$ ). These fibres were formed by several axons from cells localised in the papillae and in the anterior trunk epithelium encompassed by the papillae (Figure $3 \mathrm{~A}, \mathrm{~B}$ ). This area was particularly rich in cells containing axons (Figure $3 \mathrm{~B}$ ). A nerve-like process was revealed by the same technique in the larvae of $C$. phlegraea (Figure $3 \mathrm{H}, \mathrm{I}$ ).

Bundles of microtubules stained with anti $\beta$ tubulin antibody were present in the digitiform processes of central fusiform cells, emerging from the apices of the papillae (Figure $3 \mathrm{C}$ ).

In $C$. lepadiformis larvae, serotonin was detected by immunolocalisation in the cellular bodies of cells localised in the marginal zone of the papillae (Figure $3 \mathrm{D}, \mathrm{F}$ ). Serotonin-containing cells were arranged in a circle at the base of each papilla, as shown by the superimposition of confocal laser images to those obtained by transmission microscopy (Figure $3 \mathrm{E}$ ). By double immunolocalisation of serotonin and $\beta$-tubulin, it was shown 

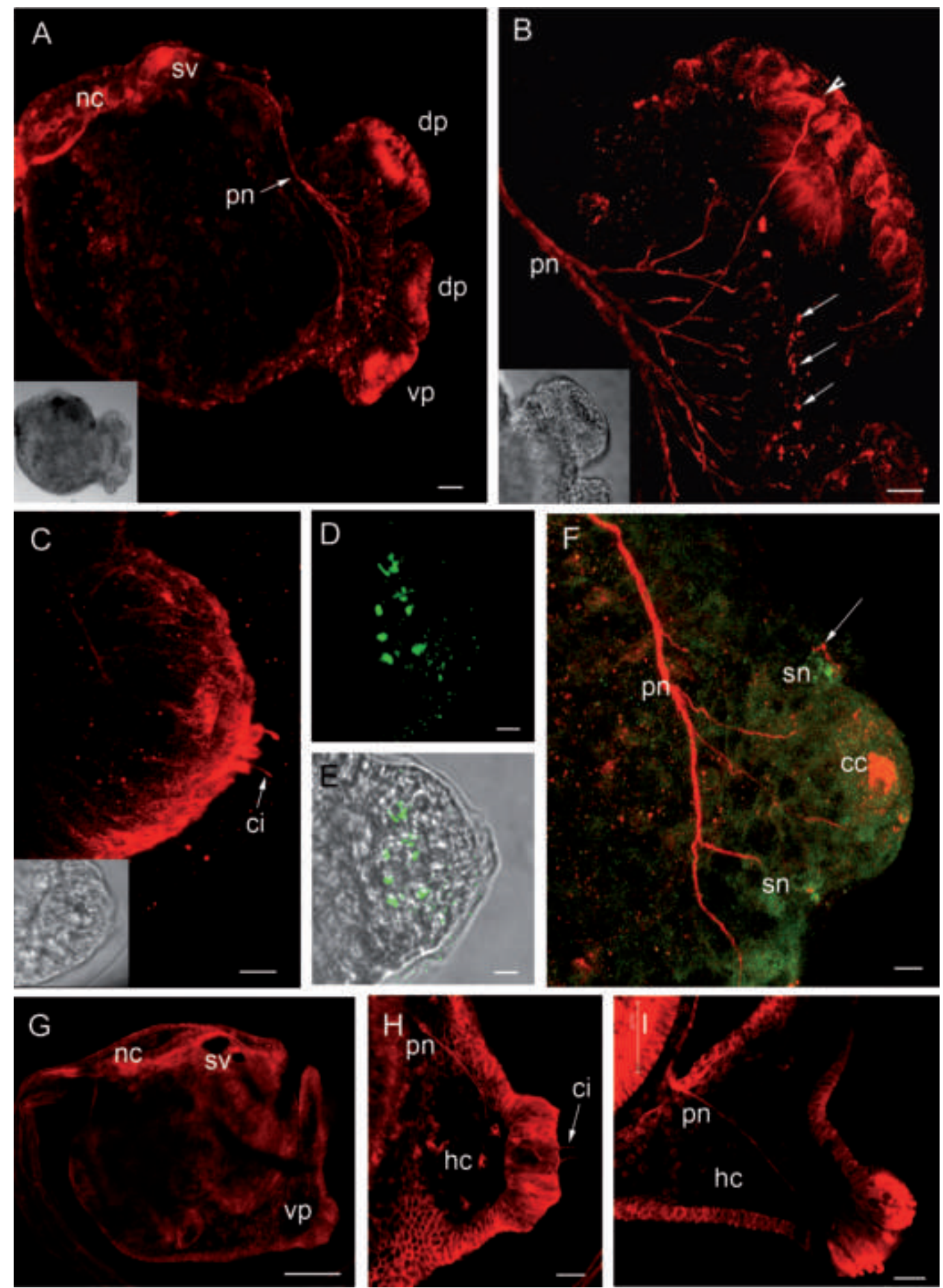

Figure 3. Confocal laser images of the larvae of Clavelina lepadiformis (A-F) and Clavelina phlegraea (G-I) showing the localisation of $\beta$ tubulin (TRITC signal, in red) and of serotonin (FITC signal, in green). The inserts show the corresponding light microscopy images. (A) Image of the trunk region showing that the whole nervous system is labelled by anti $\beta$-tubulin antibody. It is possible to see the papillary nerve (pn) that extends to the sensory vesicle (sv). (B) Magnification of the dorsal papilla showing several axon-like processes emerging from cells located in the peripheral region of the papilla (arrowhead) and in the region encompassed by the papillae. These cells bear cilia (arrows). (C) Lateral view of a papilla showing the microvilli and the cilia emerging from central cells. (D) Serotonin localisation in a papilla. Several cellular bodies are positive. (E) Superimposition of D to light microscopy image. (F) Double immunolocalisation showing central $\beta$-tubulin-positive cells and peripheral serotonin-positive cells bearing cilia (arrow). Axons emerging from these cells join together to form the papillary nerve. (G) Image of the trunk region of $C$. phlegraea larva showing an anti $\beta$-tubulin-positive signal in the central nervous system. (H) Magnification of a ventral papilla in which it is possible to observe the papillary nerve and the cilia borne by the central cells. (I) Anterior trunk region of $C$. phlegraea larva showing the papillary nerve that runs through the haemocoelic cavity. cc: central cells; ci: cilia; dp: dorsal papilla; hc: haemocoelic cavity; nc: nerve cord; sn: serotonergic neurons; vp: ventral papilla. Scale bar: A, H, I 20 um; B, C, D, E, F $10 \mu \mathrm{m} ; \mathrm{G} 100 \mu \mathrm{m}$. 
A

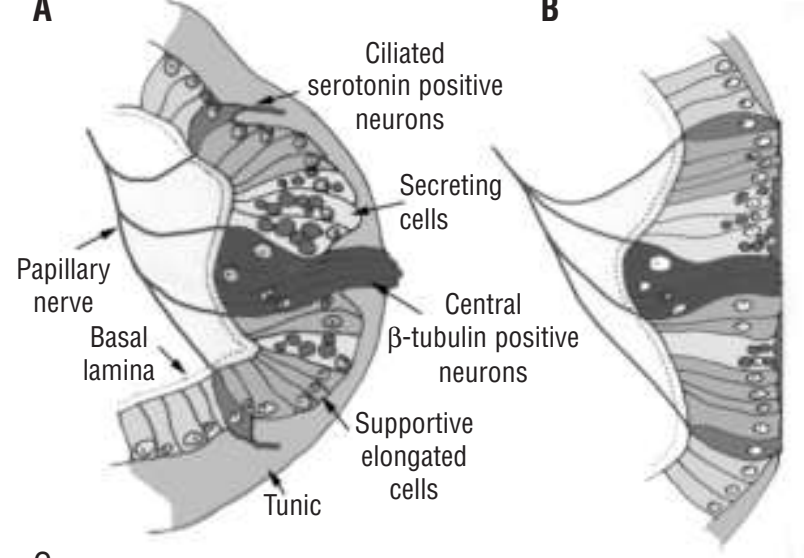

B

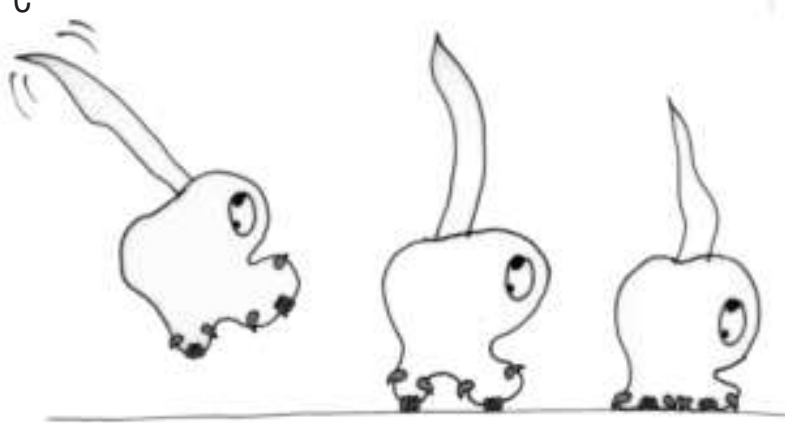

Figure 4. Schematic drawing of an adhesive papilla of Clavelina lepadiformis before (A) and after (B) papillary retraction. (C) Schematic drawing of the different phases of settlement via the proposed mechanism (see text for details). that both serotonin-containing cells and central fusiform cells have axons processes that contribute to formation of the papillary nerves (Figure $3 \mathrm{~F}$ ). Moreover, peripheral serotonin-positive cells bear cilia, stained by anti $\beta$-tubulin antibody, which protrude into the tunic (Figure $3 \mathrm{~F}$ ). Serotonin was not localised in C. phlegraea larvae.

The morphology of the papillae of $C$. lepadiformis as indicated by our analysis is schematised in Figure $4 \mathrm{~A}$. The papillae are formed by at least four different cell types: the central fusifom neurons, labelled with $\beta$-tubulin, possessing elongated sensory-like projections which reach the apex of the papilla and whose axons contribute to formation of the papillary nerves; the elongated vesiclerich cells surrounding the central neurons; the elongated supporting cells; and the peripheral serotonin-positive neurons, whose axons are labelled with $\beta$-tubulin and contribute to formation of the papillary nerves.

\section{Discussion}

This work has demonstrated, for the first time, that the adhesive papillae of the Clavelina genus are not simple bulbous papillae (Turon, 1991) but are complex structures. In fact, they are formed by different cell types: mucus-secreting cells, supporting cells and at least two types of neuron. The adhesive papillae of the two analysed species are similar both in their histological and immunohistochemical features. The most striking difference is the presence of a hyaline cup in the papillae of $C$. phlegaea that has never been observed in $C$. lepadiformis. Since the secreting cells of $C$. phlegraea contain smaller vesicles than those present in the secretory cells of $C$. lepadiformis, we suggest that in the former species the adhesive material is rapidly discharged into the hyaline cup, which is the ultimate storage device for the papillae of this species. Instead, in C. lepadiformis the mucus may be stored in the large vesicles of the secretory cells until the attachment phase has begun. These differences may be linked to the preference for different habitats that is shown by the two species. For example, in the same location in the Taranto Sea, C. lepadiformis prefers to settle on shaded surfaces (Tursi et al., 1977) unlike C. phlegraea, which, along with Polyandrocarpa zorritensis, is characteristic of the ascidio-fauna of the very superficial waters (0.5 $\mathrm{m}$ depth) (Mastrototaro et al., 2008).

The secretory cells are clustered in the central body of the papilla and surround the central fusiform neurons. There are also elongated cells with a supportive function scattered in the papillar body.

In C. lepadiformis, two types of neurons were identified: neurons of the first type were labelled with $\beta$-tubulin, are located in the core of the papilla and their terminals emerge from the apex of the papilla. They will be termed central neurons. These neurons are similar to the axial cells bearing microvilli, as previously described in many species ( Phallusia mammillata, Sotgia et al., 1998; Ascidia callosa, Burighel and Cloney, 1997; Ascidia malaca, Gianguzza et al., 1999; Polysyncraton lacazei, Diplosoma spongiformis, Ecteinascidia turbinata, Turon, 1991). The interpretation of these cells has long been problematic. Torrence and Cloney (1983), who observed similar cells in Distaplia occidentalis, proposed that their role may be strictly supportive. Burighel and Cloney (1997) reported 
that the microvilli of the axial cells provide a large surface area for the attachment of the adhesives. Cloney (1977) and Turon (1991) suggested that a sensory function for axial cells was also possible. Results from our analysis allowed us to assign them a definite sensory capacity. In fact, we demonstrated the presence of axons processes labelled with $\beta$ tubulin, emerging from these cells and joining to form the papillary nerve.

We also identified a second type of neuron that was labelled with $\beta$-tubulin and is localised at the border of the papilla. These cells form a ring. They bear cilia that emerge from the papilla, near its base. In C. phlegraea, we observed the cilia and the papillary nerve in histological sections. In C. lepadiformis, these neurons contain serotonin, and therefore they will be termed peripheral serotonergic neurons. We were not able to immunolocalise serotonin in C. phlegraea larvae. We cannot rule out the possibility that this could be due to technical problems, perhaps linked to the fixation procedure. In fact, it is known that serotonin is a highly unstable molecule that can be easily oxidised. But it is also possible that analysed specimens contain low levels of serotonin that could not be detected by the method used.

Our analysis demonstrated that the papillae of Clavelina larvae also have a sensory function, and it is thus correct to term them sensory and glandular papillae. In a previous description, it was reported that the papillae of $C$. lepadiformis do not contain axial columnar cells with microvilli and sensory cells but only secretory cells (Turon, 1991). It is possible that this description referred to incompletely developed papillae. In fact, it is known that in other ascidian species the larvae complete their development after hatching and in particular that the adhesive organs undergo specific maturation (Sotgia et al., 1998; Chiba et al., 2004).

Recently, we described the presence of two types of neurons in the papillae of the larvae of Botrylloides leachi, a compound ascidian (Pennati et al., 2007). In this species, the papillae have only a sensory function, while the secretory cells are clustered in a glandular organ located in the area encompassed by the three papillae. Notably, these sensory papillae contain central $\beta$-tubulin-positive neurons, whose terminal endings emerge from the apices of the papillae, and peripheral serotonin-positive neurons, a condition strikingly similar to that observed in C. lepadiformis. In accordance with what was proposed for Botrylloides leachi, we believe that in $C$. lepadiformis the two types of neurons may also play different roles during settlement. In fact, the papillae of ascidian larvae perform a mechanosensory function when participating in substrate selection (Groppelli et al., 2003), and are also involved in the mechanism that triggers metamorphosis (Burighel and Cloney, 1997; Zega et al., 2005). It is reasonable to suppose that the central neurons may play a role in substrate selection and may be chemo or mechanoreceptors. Besides, their terminal endings protrude from the apex of the papilla and they are the first cells to come into contact with the substrate when the larva explores it by quick touches. In contrast, the terminal endings of the peripheral neurons do not contact the substrate during this exploratory period. They are stimulated only after the larva has attached to the substrate, by means of the secreted mucus, and the papillae are retracted, pulling the larva closer to the substrate itself (Figure $4 \mathrm{~B}, \mathrm{C}$ ). Consequently, it is possible to hypothesise that, when the adhesion becomes permanent, these neurons and those present in the area encompassed by the three papillae are stimulated and may participate in the signalling cascade that triggers metamorphosis, possibly by releasing a signalling molecule. Serotonin could be this molecule, since it has been reported in other ascidian species (Pennati et al., 2001; Stach, 2005; Pennati et al., 2007). Moreover, serotonin is known to stimulate metamorphosis in the larvae of many animal phyla (Couper and Leise, 1996; Walther et al., 1996; Yamamoto et al., 1999), including ascidians (Zega et al., 2005).

It is worth noting that different kinds of neurons have also been observed in other ascidian species. Cloney and Torence (1984) described the ultrastructure of the adhesive papillae of Diplosoma macdonaldi, and reported the presence of one type of primary sensory cells, called anchor cells, whose cilia and microvilli insert into the tunic, and a second type of more internal neurons whose cilia do not reach the outer layer of the tunic, at least in noneverted papillae. In Polysyncraton lacazei larvae, the cup-shaped papillae bear ciliated cells in the proximal half of the marginal layer of the cup that is in an unexposed position (Turon, 1991).

Thus, it is possible that the presence of different neurons with different functions is a feature shared by many species, suggesting that the adhesive papillae of ascidian larvae are more complex than generally believed. 


\section{Acknowledgments}

The confocal microscopy images were obtained using the facilities of C.I.M.A. (Advanced Microscopy Centre of the University of Milan). We thank Dr. Umberto Fascio for the confocal microscopy images. The study was supported by grants from the University of Milan (FIRST 2007).

\section{References}

Brown ER, Nishino A, Bone Q, Meinertzhagen IA, Okamura Y. GABAergic synaptic transmission modulates swimming in the ascidian Iarva. Eur J Neurosci 2005;22:2541-8.

Brunetti R. Species of Clavelina in the Mediterranean Sea. Annales de I'Institut Océanographique, Paris 1987;63:101-8.

Burighel P, Cloney RA. Urochordata: Ascidiacea. In Microscopic Anatomy of Invertebrates, Wiley-Liss Inc 1997;15:221-347.

Chiba S, Sasaki A, Nakayama A, Takamura K, Satoh N. Development of Ciona intestinalis juveniles (through 2 nd ascidian stage). Zool Sci 2004;21:285-98.

Cloney RA. Larval adhesive organs and metamorphosis in ascidians. I. Fine structure of the everting papillae of Distaplia occidentalis. Cell Tissue Res 1977;183:423-44.

Cloney RA. Larval adhesive organs and metamorphosis in ascidians. II. The mechanism of eversion of the papillae of Distaplia occidentalis. Cell Tissue Res 1979;200:453-73.

Cloney RA and Torrence SA. Ascidian larvae: structure and settlement. In JD Costlow and RC Tipper (eds.) Marine Biodeterioration: An Interdisciplinary Study. Annapolis, Md. Naval Institute Press 1984; 141-8.

Couper JM, Leise EM. Serotonin injections induce metamorphosis in larvae of the gastropod Ilyassana obsoleta. Biol Bull 1996; 191:178-86.

Gianguzza M, Dolcemascolo G, Fascio U, De Bernardi F. Adhesive papillae of Ascidia malaca swimming larvae: investigations on their sensory function. Invertebr Reprod Dev 1999;35:239-50.

Groppelli S, Pennati R, Scarì G, Sotgia C, De Bernardi F. Observations on the settlement of Phallusia mammillata larvae: effects of different lithological substrata. Ital J Zool 2003;70:321-6.

Imai $\mathrm{JH}$ and Meinertzhagen IA. Neurons of the ascidian larval nerv- ous system in Ciona intestinalis. II. Peripheral nervous system. J Comp Neurol 2007;501:335-52.

Mastrototaro F, D'Onghia G, Tursi A. Spatial and seasonal distribution of ascidians in a semi-enclosed basin of the Mediterranean Sea. JMBA 2008;8:1053-61.

Pennati R, Groppelli S, Sotgia C, Candiani S, Pestarino M, De Bernardi F. Serotonin localization in Phallusia mammillata larvae and effect of 5-HT antagonists during larval development. Dev Growth Differ 2001;43:647-56.

Pennati R, Zega G, Groppelli S, De Bernardi F. Immunohistochemical analysis of the adhesive papillae of Botrylloides leachi (Chordata, Tunicata, Ascidiacea). Ital J Zool 2007;74:325-9.

Sotgia C, Fascio U, Melone G, De Bernardi F. Adhesive papillae of Phallusia mammillata larvae: morphology and innervation. Zool Sci 1998; 15:363-70.

Stach T. Comparison of the serotonergic nervous system among Tunicata: Implication of its evolution within Chordata. Org Divers Evol 2005;5:15-24.

Svane I and Young CM. The ecology and behaviour of ascidian larvae. Oceanogr Mar Biol Annu Rev 1989;27:45-90.

Takamura K. Nervous network in larvae of the ascidian Ciona intestinalis. Dev Genes Evol 1998;208: 1-8.

Torrence SA and Cloney RA. Ascidian larval nervous system: primary sensory neurons in adhesive papillae. Zoomorphology 1983;102: 111-23.

Turon X. Morphology of the adhesive papillae of some ascidian larvae. Cah Biol Mar 1991;32:295-309.

Tursi A, Matarrese A, Scalera Liaci L. Fenomeni d'insediamento in Clavelina lepadiformis (Müller) (Tunicata). Oebalia 1977;3:3-16.

Walther M, Ulrich R, Kroiher M, Berking S. Metamorphosis and pattern formation in Hydractinia echinata, a colonial hydroid. Int $J$ Dev Biol 1996;40:313-22.

Yamamoto H, Shimizu K, Tachibana A, Fusetani N. Roles of dopamine and serotonin in larval attachment of the barnacle, Balanus amphitrite. J Exp Zool 1999;284:746-58.

Young CM and Braithwaite LF. Larval behaviour and post-settling morphology in the ascidian Chelyosoma productum Stimpson. J Exp Mar Biol Ecol 1980;42:157-69.

Zega G, Pennati R, Groppelli S, Sotgia C, De Bernardi F. Dopamine and serotonin modulate the onset of metamorphosis in the ascidian Phallusia mammillata. Dev Biol 2005;282:246-56.

Zega G, Biggiogero M, Groppelli S, Candiani S, Oliveri D, Parodi M, et al. Developmental expression of glutamic acid decarboxylase and of gamma-aminobutyric acid type $B$ receptors in the ascidian Ciona intestinalis. J Comp Neurol 2008;506:489-505. 
R. Pennati et al.

34 